\title{
Intraoperative diagnosis of sentinel lymph node metastases in breast cancer treatment with one-step nucleic acid amplification assay (OSNA)
}

Paweł Szychta ${ }^{1}$, Bogusław Westfal ${ }^{1}$, Rafał Maciejczyk ${ }^{1}$, Beata Smolarz ${ }^{2}$, Hanna Romanowicz ${ }^{2}$, Tomasz Krawczyk², Marek Zadrożny ${ }^{1}$

${ }^{1}$ Department of Oncological Surgery and Breast Diseases, Institute of Polish Mother's Memorial Hospital, Lodz, Poland

${ }^{2}$ Laboratory of Molecular Genetics, Department of Pathology, Institute of Polish Mother's Memorial Hospital, Lodz, Poland

Submitted: 17 December 2014

Accepted: 21 February 2015

Arch Med Sci 2016; 12, 6: 1239-1246

DOI: 10.5114 /aoms.2016.62902

Copyright (c) 2016 Termedia \& Banach

\section{Abstract}

Introduction: The aim of the study was to evaluate the clinical usefulness of a one-step nucleic acid amplification assay (OSNA) for intraoperative detection of metastases to sentinel lymph nodes (SLNs) in comparison to examination of frozen sections, and to summarize the results of previous studies. Material and methods: We enrolled 98 patients aged $58.13 \pm 10.74$ years treated surgically for breast cancer, and 99 biopsies of SLNs were followed by analysis of 105 SLNs. The central $1 \mathrm{~mm}$ slice of SLN was used for examination of frozen sections, whereas 2 outer slices of SLNs were analyzed intraoperatively with OSNA. Detection of isolated tumor cells (ITC), micrometastases or macrometastases with OSNA extended surgery to axillary lymph node dissection. Congruency of results was assessed between OSNA and examination of frozen sections.

Results: One-step nucleic acid amplification assay detected metastases in 29/105 SLNs in surgery of 27/99 breasts, including ITC in 3/29 SLNs, micrometastases in $12 / 29$ and macrometastases in 14/29. One-step nucleic acid amplification assay detected significantly more metastases to SLNs than examination of frozen sections $(p<0.0001)$. All 8 inconsistent results were positive in OSNA and negative in examination of frozen sections; ITC were identified in $2 / 8$ SLNs and micrometastases in $6 / 8$ SLNs. Sensitivity for OSNA was calculated as $100 \%$, specificity as $90.47 \%$, and $\kappa$ was $79.16 \%$.

Conclusions: One-step nucleic acid amplification assay analysis allows rapid and quantitative detection of mRNA CK19 with high specificity and a low rate of false positives. One-step nucleic acid amplification assay is a reliable tool for intraoperative diagnosis of whole SLNs during surgery of breast cancer. One-step nucleic acid amplification assay minimizes the need for secondary surgery and avoids delays in the adjuvant treatment.

Key words: breast cancer, sentinel lymph node, intraoperative molecular study, cytokeratin 19.

\section{Introduction}

Intraoperative evaluation of sentinel lymph nodes (SLNs) in the surgical treatment of breast cancer is based on microscopic examination

\author{
Corresponding author: \\ Prof. Marek Zadrożny MD, \\ $\mathrm{PhD}$ \\ Department \\ of Oncological Surgery \\ and Breast Diseases \\ Institute of Polish \\ Mother's Memorial Hospital \\ 281/289 Rzgowska St \\ 93-338 Lodz, Poland \\ Phone: +48 422711101 \\ E-mail: zadrozny.lodz@wp.pl
}


of frozen sections, which unfortunately does not allow for accurate diagnosis in all cases [1].

Recently described intraoperative molecular methods for the detection of metastatic breast cancer to SLN detect mRNA expression of the epithelial marker cytokeratin 19 (CK19) [2-6]. CK19 is normally absent in the lymph node and its high level of expression is seen in the majority of breast cancer cells. The number of copies of mRNA for CK19 can be assessed with the one-step nucleic acid amplification test (OSNA). Sensitivity and specificity of the OSNA test for the detection of metastases has been shown in a few studies using different research protocols [7-10]. The results of previous reports should be summarized in order to propose standards for treatment of breast cancer together with validation of the intraoperative SLN evaluation using OSNA in the clinical setting.

The aim of this study was to evaluate the clinical usefulness of OSNA for the intraoperative detection of metastasis in SLN in comparison to the examination of frozen sections with $\mathrm{H}+\mathrm{E}$ staining, as well as to summarize the results of previous research in this area.

\section{Material and methods}

A prospective study was conducted from May 2011 to July 2012 after the approval of the Ethics Committee of the Institute of Polish Mother's Memorial Hospital, Lodz, Poland. Inclusion criteria were: preoperatively diagnosed monofocal breast cancer at stage less than T3, no neoadjuvant systemic chemotherapy or hormone therapy, no previous surgery to the affected breast in the past and no clinically detected metastases (TIS-T2NOMO, according to the $6^{\text {th }}$ edition of the Tumor-Node-Metastasis (TNM) cancer staging classification) [11]. One patient with pT3 took part in the study because the tumor size was underestimated before surgery.

Preoperatively patients were subjected to examination of the axilla with ultrasound (US), which was part of staging. On the day of surgery we administered subcutaneously $2 \mathrm{ml}$ of blue dye (2.5\% Patentblau V, Guerbet, Aulnay-sous-Bois, France) above the tumor [12]. After a mastectomy

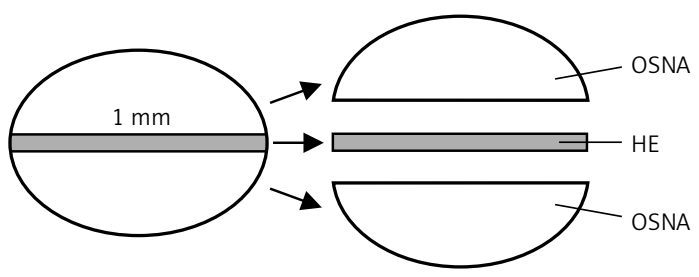

Figure 1. A 1-mm-thick slice was cut out from the longitudinal central part of the sentinel lymph node for staining with hematoxylin and eosin $(\mathrm{H}+\mathrm{E})$, and the remaining parts were examined by using the one-step nucleic acid amplification (OSNA) assay or breast conserving surgery SLNs were identified and removed using a well-known surgical technique. Up to 4 SLN were identified and removed per patient (1.12 sentinel nodes on average).

The central $1 \mathrm{~mm}$ slice of SLN was removed with a Sysmex cutting device and was used for examination of frozen sections with $\mathrm{H}+\mathrm{E}$ staining (Figure 1). The two outer slices of the node were analyzed intraoperatively with a OSNA. The method of analysis of CK19 mRNA expression using OSNA has been previously described in detail [10]. After purification from the surrounding tissues, lymph nodes are homogenized in the mRNA stabilizing solution Lynorhag (Sysmex). The resulting homogenate is subjected to isothermal amplification $\left(65^{\circ} \mathrm{C}\right)$ of cytokeratin 19 (CK19) for 16 min with a Lynoamp kit (Sysmex) through a reverse transcriptase amplification test (RT-LAMP) in the amplification detector RD-100i (Sysmex) [13]. The isothermal reaction prevents amplification of genomic DNA, which would give false positive results. Sensitivity, specificity, and speed of the test are high when using six primers [14]. Samples are diluted with Lynorhag solution $(1: 10)$ to inhibit the activity of substances inhibiting the amplification (such as adipose tissue) [6]. The analysis can be performed on up to four parallel lymph nodes. Total time from preparing the specimen to obtaining results is $30 \mathrm{~min}$ for one lymph node and 40 min for four lymph nodes [15]. The qualitative result of CK19 (negative or positive) and quantitative result (number of copies of CK19 mRNA/1 $\mu \mathrm{l}$ lysate) determined the status of the lymph nodes: number of copies $<250=$ no metastases (qualitative result: negative “-", quantitative result <250) or isolated tumor cells (ITC) (positive “+”, < 250), number of copies 250-5000 = micrometastases (positive “+", 250-5000), and number of copies $>5000$ = macrometastases (positive “++", > 5000).

Intraoperative analysis of the SLN using OSNA determined the further surgical treatment. Isolated tumor cells (ITC), micro-and macrometastases described the SLN as positive (SLN+). In the case of $\mathrm{SLN}+$, the operation was extended to further axillary lymph node dissection (ALND) [12]. The breast specimen with a tumor was sent for postoperative histological examination with assessment of the activity of estrogen and progesterone receptors and HER2.

The electronic database included: the patient's personal data, histological diagnosis of the tumor, staging according to the sixth edition of the TNM classification, grading, the number of isolated SLNs, diagnosis from examination of frozen sections, diagnosis using OSNA, number of mRNA CK19 copies/ $\mu$ l detected by OSNA, number of lymph nodes removed in ALND, activity of estrogen and progesterone receptors, HER2 expression and presence of 
metastases in non-sentinel lymph nodes. Congruency of the results was assessed between OSNA and microscopic evaluation of frozen sections. A thorough analysis of cases was conducted where axillary lymphadenectomy was performed.

Compliance or inconsistency of the SLN metastases between results of the OSNA test and the microscopic examination of frozen sections was calculated using Cohen's “ $к$ " index. Sensitivity, specificity, positive and negative predictive values were calculated for the OSNA method with the McNemar test. Analysis of two dichotomous variables was performed with the $\chi^{2}$ test.

\section{Statistical analysis}

Statistical significance between a continuous variable and a dichotomous variable was assessed using the logistic regression test. Values of $p<$ 0.05 were considered statistically significant.

\section{Results}

In 111 patients, 112 sentinel lymph node biopsies (SLNBS) were performed and were subjected to histological and molecular evaluation of 121 SLNs. However, in 4 patients (6 SLNs) we could not obtain results of histological examination of frozen sections, and in 9 cases (10 SLNs) all SLNs were evaluated using only OSNA. Therefore, the study ultimately included 98 patients aged 58.13 \pm 10.74 years ( 29 to 87 years). Patients had 1.07 SLNs resected on average (1-2 SLNs), and one woman who had bilateral breast cancer underwent bilateral SLNB. Therefore, 105 SLNs were assessed in the study from 99 SLNBs. For all specimens, OSNA assay and microscopic examination of frozen sections were performed successfully.

Radical modified mastectomy was undertaken for $25 / 99$ (25.25\%) breasts, quadrantectomy in $42 / 99$ (42.42\%) cases and a wide local excision in 32/99 (32.32\%). Histopathological examination detected the following types of breast cancer: ductal carcinoma in situ in 6/99 (6.06\%), invasive ductal carcinoma in 74/99 (74.74\%), lobular carcinoma in situ in 2/99 (2.02\%), invasive lobular carcinoma in 5/99 (5.05\%), mucinous carci- noma in 4/99 (4.04\%) and other in 8/99 (8.08\%). According to the classification of cancer staging, Tis was observed in $8 / 99$ (8.08\%), T1 in 70/99 (70.70\%), T2 in 20/99 (20.20\%) and T3 in 1/99 (1.01\%). Based on the Bloom-Richardson grading scale, grade I was observed in 26/99 (26.26\%), II in 45/99 (45.45\%), III in 7/99 (7.07\%), it was unknown in $13 / 99(13.13 \%)$ and it was not evaluated in $8 / 99$ (8.08\%). Detailed information on the activity of estrogen receptor and progesterone receptor, HER2 expression, vascular invasion and lymphatic invasion is shown in Table I.

Microscopic examination of frozen sections with $\mathrm{H}+\mathrm{E}$ staining detected metastases to SLN in $21 / 105(20.00 \%)$ specimens. In the OSNA assay a positive result (metastasis) was obtained in $29 / 105$ (27.61\%) SLNs excised during surgery of $27 / 99$ (27.27\%) breasts, including isolated tumor cells (ITC) in $3 / 29$ (10.34\%) SLNs, micrometastases ("+") in 12/29 (41.37\%) and macrometastases ("++") in 14/29 (48.27\%) (Table II). Thus, the OSNA test detected significantly more breast cancer metastases to the SLNs than histological examination of frozen sections $\left(\chi^{2}=68.79, p<0.0001\right)$, despite the fact that the central slice of each SLN was examined by microscopic examination. Of the 8 inconsistent results of SLN status, they were all positive in OSNA and negative in the histological examination of frozen sections $(\mathrm{O}+/ \mathrm{H}-)$, and in all cases the primary tumor was invasive ductal carcinoma. Among $8 \mathrm{SLNs} \mathrm{O}+/ \mathrm{H}-$, isolated tumor cells (ITC) were identified in $2 / 8(25 \%)$ sentinel nodes, and micrometastases in 6/8 (75\%) cases. As a result, the sensitivity was calculated for OSNA as $100 \%$, specificity as $90.47 \%$, and $\kappa$ was $79.16 \%$ (Table III).

The ALND was performed during surgery of $29 / 99$ (29.2\%) breasts as a result of the positive SLN result in OSNA (Table IV). Metastases to nonSLNs were found in $1 / 3(33.3 \%)$ cases of SLNs assessed as OSNA-“+” ITC, in 4/12 (33.3\%) cases detected as OSNA-"+" micrometastasis and in 5/14 (35.7\%) who had OSNA-“++" results. Thus, the risk of non-SLN metastases was insignificantly higher for OSNA-“++" results compared to OSNA"+" overall $(p>0.05)$.

Table I. Characteristics of different parameters describing breast carcinomas

\begin{tabular}{|c|c|c|c|c|c|c|}
\hline \multirow[t]{2}{*}{ Parameter } & \multicolumn{2}{|c|}{ Positive (> 10\%) } & \multicolumn{2}{|c|}{ Negative $(<10 \%)$} & \multicolumn{2}{|c|}{ Unknown } \\
\hline & $n$ & $\%$ & $n$ & $\%$ & $n$ & $\%$ \\
\hline Estrogen receptor & $64 / 81$ & 79.01 & $17 / 81$ & 20.98 & $18 / 99$ & 18.18 \\
\hline Progesterone receptor & $59 / 81$ & 72.83 & $22 / 81$ & 27.16 & $18 / 99$ & 18.18 \\
\hline HER2 & $26 / 76$ & 34.21 & $50 / 76$ & 65.78 & $23 / 99$ & 23.23 \\
\hline Vascular invasion & $3 / 91$ & 3.29 & $88 / 91$ & 96.70 & $8 / 99$ & 8.08 \\
\hline Lymphatic invasion & $4 / 91$ & 4.39 & $87 / 91$ & 95.60 & $8 / 99$ & 8.08 \\
\hline
\end{tabular}




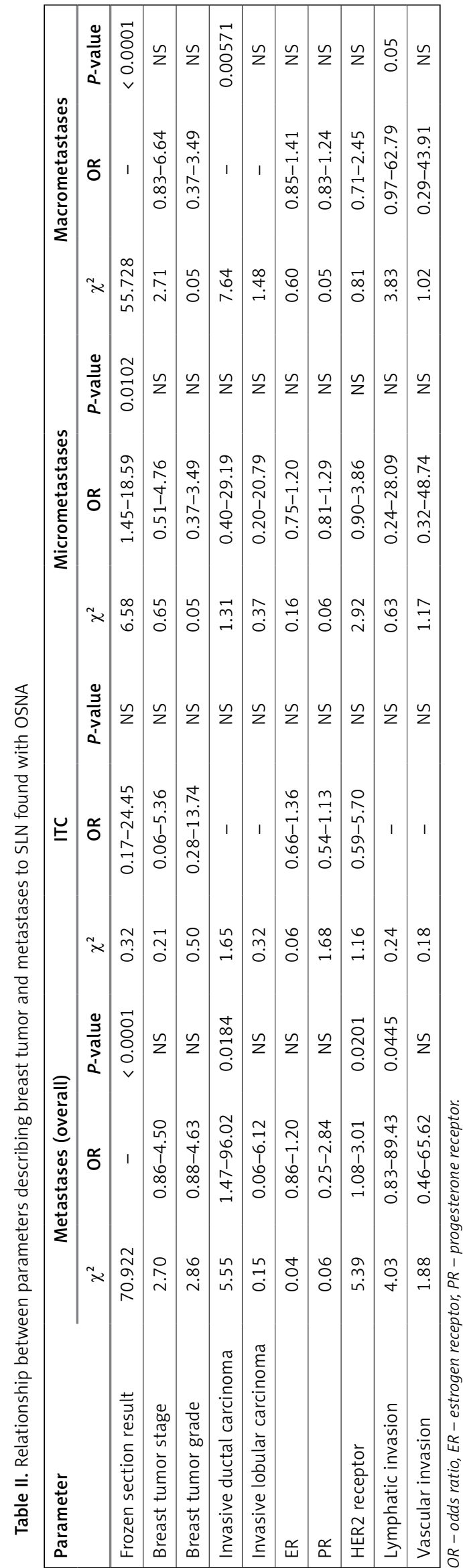

\section{Discussion}

Reliable intraoperative SLN assessment is invaluable for optimal surgical treatment of breast cancer. In the case of breast cancer metastasis to the SLN, ALND is performed simultaneously with the primary breast tumor surgery so that the patient avoids further surgery and adjuvant therapy is initiated promptly [12]. In addition, simultaneous ALND is advantageous as there is a high possibility to remove all axillary lymph nodes from the previously unchanged tissues, resulting in high reliability of the method. In contrast, delayed ALND is associated with lymph node dissection in the scar tissue formed after previous SLNB. Intraoperative analysis of the SLN is economically advantageous, and the implicit savings result from the reduced number of hospitalizations and avoided secondary surgery, which compensates for the cost of the intraoperative OSNA assay [16].

In our study, microscopic examination of SLNs from frozen sections was compared with the OSNA test to detect a more reliable method supporting the intraoperative decision of simultaneous ALND. Histological examination of frozen sections assesses SLN only in the selected two-dimensional sections with the risk of false-negative results, particularly in the case of micrometastases [3, 17]. There are also difficulties in the diagnosis of metastases to SLNs in invasive lobular carcinoma [18]. Accordingly, the sensitivity of the intraoperative histological examination has been designated for macrometastases at a high level from $84 \%$ to $94 \%$, while for micrometastases there is a wide range from $17 \%$ to $92 \%$ [1]. In about $20 \%$ of cases with a negative SLN result of the intraoperative histological examination, a positive result of postoperative full histological examination resulted in deferred ALND [14].

Therefore the advantage of SLNB is accurate staging classification and detection of patients requiring $A L N D$. If patients with SLN metastases have missed early ALND, they are prone to breast cancer recurrence and/or distant metastases because of the risk of non-SLN metastases. In our study, analysis of SLN showed ITC or micrometastases in 14\% of cases and macrometastases in $13 \%$, and all of these patients required ALND with adjuvant systemic therapy. Histological examination of axillary nodes showed metastatic nonSLNs in 33\% of cases with an OSNA-"+" result (ITC and micrometastases) and $35 \%$ of patients with OSNA-“++". Previous reports described non-SLNs metastases in the range from $13 \%$ to $22 \%$ of patients with SLN micrometastases and from $45 \%$ to $79 \%$ of patients with SLN macrometastases [19].

Conversely, SLNB also aims to select patients who do not require ALND. As previously reported, approximately $60 \%$ of patients with positive SLNs 
Intraoperative diagnosis of sentinel lymph node metastases in breast cancer treatment with one-step nucleic acid amplification assay (OSNA)

Table III. Contingency table and concordance between OSNA assay results andp; $\chi^{2}=68.79, p<0.0001$

\begin{tabular}{|lcccccc|}
\hline Result of SLN assessment & \multicolumn{7}{c|}{ OSNA } \\
\cline { 2 - 7 } & \multicolumn{2}{c}{ Positive } & \multicolumn{2}{c|}{ Negative } & \multicolumn{2}{c|}{ Total } \\
\cline { 2 - 7 } & $n$ & $\%$ & $n$ & $\%$ & $n$ & $\%$ \\
\hline Positive & $21 / 105$ & 20.00 & $0 / 105$ & 0.00 & $21 / 105$ & 20.00 \\
\hline Negative & $8 / 105$ & 7.61 & $76 / 105$ & 72.38 & $84 / 105$ & 80.00 \\
\hline Total & $29 / 105$ & 27.61 & $76 / 105$ & 72.38 & & \\
\hline
\end{tabular}

Table IV. Risk of non-sentinel lymph node metastasis in one-step nucleic acid assay-positive patients who undergo axillary dissection

\begin{tabular}{|lcccccccc|}
\hline OSNA array results & \multicolumn{3}{c}{$\begin{array}{c}\text { Axillary dissection } \\
\text { after SLNB }\end{array}$} & \multicolumn{3}{c|}{ Non-SLN metastases } \\
\cline { 2 - 9 } & $n$ & $\%$ & $\begin{array}{c}\text { AvLNs } \\
\text { (min.-max.) }\end{array}$ & $\begin{array}{c}\text { Present } \\
n\end{array}$ & $\begin{array}{c}\text { Present } \\
\%\end{array}$ & $\begin{array}{c}\text { AvLNs } \\
(\text { min.-max.) }\end{array}$ & $\begin{array}{c}\text { Absent } \\
n\end{array}$ & $\begin{array}{c}\text { Absent } \\
\%\end{array}$ \\
\hline Positive (+ and ++) & $29 / 99$ & 29.2 & $\begin{array}{c}9.46 \pm 4.08 \\
(4-19)\end{array}$ & $10 / 29$ & 34.4 & $\begin{array}{c}1.50 \pm 0.97 \\
(1-4)\end{array}$ & $19 / 29$ & 65.5 \\
\hline ITC & $3 / 29$ & 10.3 & $\begin{array}{c}13.50 \pm 4.94 \\
(10-17)\end{array}$ & $1 / 3$ & 33.3 & $\begin{array}{c}4 \\
(n=1)\end{array}$ & $2 / 3$ & 66.6 \\
\hline+ & $12 / 29$ & 41.3 & $\begin{array}{c}8.90 \pm 3.95 \\
(5-16)\end{array}$ & $4 / 12$ & 33.3 & $\begin{array}{c}1.66 \pm 0.57 \\
(1-2)\end{array}$ & $8 / 12$ & 66.6 \\
\hline++ & $14 / 29$ & 48.2 & $\begin{array}{c}9.30 \pm 3.98 \\
(4-19)\end{array}$ & $5 / 14$ & 35.7 & $\begin{array}{c}1.00 \pm 0.00 \\
(1-1)\end{array}$ & $9 / 14$ & 64.2 \\
\hline
\end{tabular}

AvLNs - average number of lymph nodes \pm standard deviation, min.-max. - minimum-maximum.

Table V. Concordance of OSNA with histological examination - summary

\begin{tabular}{|c|c|c|c|c|c|c|c|c|c|}
\hline \multirow{2}{*}{\multicolumn{2}{|c|}{ Parameter }} & \multicolumn{7}{|c|}{ Previous reports } & \multirow{2}{*}{$\begin{array}{l}\text { Our } \\
\text { study }\end{array}$} \\
\hline & & {$[6]$} & [7] & [9] & {$[14]$} & {$[15]$} & {$[16]$} & {$[27]$} & \\
\hline \multicolumn{2}{|l|}{ Country } & Italy & UK & Germany & France & Spain & NY, USA & France & Poland \\
\hline \multirow{2}{*}{$\begin{array}{l}\text { Histological } \\
\text { examination }\end{array}$} & Intraoperative & - & - & - & - & + & + & + & + \\
\hline & Postoperative & + & + & + & + & + & + & + & - \\
\hline \multicolumn{2}{|c|}{ No. of cases/specimens } & $110 / 131$ & $203 / 412$ & & $46 / 80$ & $-/ 181$ & & $233 / 503$ & $99 / 105$ \\
\hline \multicolumn{2}{|c|}{ Rate of negative nodes with OSNA } & 71 & & & & & & & 72.38 \\
\hline \multicolumn{2}{|c|}{ Rate of micrometastases with OSNA } & 18 & & & & & & & 14.28 \\
\hline \multicolumn{2}{|c|}{ Rate of macrometastases with OSNA } & 11 & & & & & & & 13.33 \\
\hline \multicolumn{2}{|l|}{ Sensitivity } & 93.75 & 91.7 & 98.1 & 88.2 & 98.2 & 82.7 & 91.4 & 100 \\
\hline \multicolumn{2}{|l|}{ Specificity } & 83.47 & 96.9 & 91.7 & 98.4 & 94.8 & 97.7 & 93.3 & 90.47 \\
\hline \multicolumn{2}{|c|}{ Overall concordance } & & 96.0 & 91.8 & 96.3 & 99.45 & 95.8 & & \\
\hline \multicolumn{2}{|l|}{ Kappa } & 52 & & & & & & & 79 \\
\hline \multirow{2}{*}{$\begin{array}{l}\text { Predictive } \\
\text { value }\end{array}$} & Positive & 44 & 86.8 & & & & & & 72 \\
\hline & Negative & 99 & 98.1 & & & & & & 100 \\
\hline \multirow{2}{*}{$\begin{array}{l}\text { Discordant } \\
\text { cases }\end{array}$} & OSNA(+)/Hist-pat (-) & $11 / 131$ & $10 / 412$ & & & & & & $8 / 105$ \\
\hline & OSNA(-)/Hist-pat (+) & $1 / 131$ & $6 / 412$ & & & & & & $0 / 105$ \\
\hline \multirow[t]{3}{*}{$\begin{array}{l}\text { Time required } \\
\text { for OSNA }\end{array}$} & Mean & & $\begin{array}{l}32(\mathrm{I})- \\
62(\mathrm{IV})\end{array}$ & & & 39.6 & & & $\begin{array}{c}\text { Not } \\
\text { assessed }\end{array}$ \\
\hline & Min. & & $\begin{array}{l}22(I)- \\
46(I V)\end{array}$ & & & 26 & & & \\
\hline & Max. & & $\begin{array}{l}90(\mathrm{IV})- \\
97(\mathrm{I})\end{array}$ & & & 70 & & & \\
\hline
\end{tabular}


had no metastatic non-SLNs, and theoretically they did not require ALND $[19,20]$. In our study, $65 \%$ of patients who were identified in the OSNA test with SLN metastases had no metastatic nonSLNs. A study on a large series of cases could determine the cut-off point with a semi-quantitative OSNA assay to select patients who do not need additional ALND. At present, we suggest performing ALND in patients with positive OSNA qualitative and semi-quantitative results, especially in cases of macrometastases.

Sentinel lymph nodes tumor volume is considered an important factor in the prognosis of nonSLN metastasis [20]. Tumor volume in SLN is easily evaluated semi-quantitatively in OSNA, in contrast to histological examination. Micrometastases can be reliably found with OSNA because the whole SLN can be used for analysis in everyday clinical practice, which is an advantage over conventional histological examination [21]. A summary of 58 studies indicated that the presence of metastases in the axillary lymph nodes with a diameter less than $2 \mathrm{~mm}$ was associated with a worse prognosis [22]. The MIRROR (Micrometastases and Isolated Tumor Cells) study also indicated that both the presence of isolated tumor cells (ITC) and micrometastases in axillary lymph nodes were associated with worse prognosis in patients with early-stage breast cancer and not subjected to adjuvant systemic therapy [23].

The disadvantage of the OSNA method is homogenization of SLN and the associated lack of further possibility of histological evaluation. Thus, the same sample cannot be analyzed by both molecular OSNA analysis and subsequent postoperative histological examination [4]. Due to different parts of SLN used for analysis in each of the two methods, inconsistent results were described before between the OSNA test and histological examination $[6,15,24]$. In the study by Snook et al., a positive result of SLN in the OSNA test and negative histological examination of paraffin blocks were found in 8 of 204 patients, and the results of SLN in 5 of 204 patients were described as negative in OSNA and positive in histology [7]. The above patients either had been subjected to unnecessary ALND and potentially additional adjuvant treatment or the required ALND and adjuvant therapy had been missed. In the present study, 8 of the 105 SLN results were inconsistent between histology (negative result) and OSNA (positive result). No cases were inconsistent with a negative OSNA result and positive histology. Based on the results of our study, the overall OSNA sensitivity was $100 \%$ and specificity $90.47 \%$, which confirms the previously described OSNA sensitivity range from $82.7 \%$ to $98.2 \%$, and specificity from $83.47 \%$ to $98.4 \%$ (Table V) $[6,7,9,13,14,15,25]$. Based on the high concordance between histology and
OSNA observed in our study, the whole SLNs in our department are now sent for molecular analysis only. The disadvantage, however, is the resulting lack of lymph node tissue for pathology examination of potential diseases other than metastasis of breast cancer [12].

The analysis of the SLN only with OSNA is associated with the risk of false negative results due to the presence of breast cancer metastases which have no CK19 expression [6]. Low CK19 protein expression in breast cancer has been described in $1.6 \%$ to $11.1 \%$ of cases, and the lack of CK19 expression was associated with the triple-negative phenotype of breast cancer (ER-, PR-, HER2-) [6, 26-28]. In a series of 197 breast cancers, Vilardell et al. found no expression of CK19 in 0\% to $4.2 \%$ of patients, depending on the phenotype of breast cancer [29]. Micropapillary, apocrine, mucous, medullary and mixed cancers had CK19 expression in $100 \%$ of cases after $\mathrm{H}+\mathrm{E}$ staining of the whole specimen due to the focal expression of the protein. The previously described discrepancy between OSNA and histology, due to the lack of CK19 mRNA expression, was very low and ranged from $0.1 \%$ to $0.5 \%$ of lymph nodes [30]. In order to avoid false negative results, a biopsy of the primary tumor prior to surgery may include routine evaluation of CK19 expression. However, the expression of mRNA and protein may differ between the main tumor and the metastatic site. Histological examination of the one saved slice of SLN (not taken for OSNA analysis) negates this risk and, therefore, the $1 \mathrm{~mm}$ central part of the SLN was evaluated in our study with histology before the OSNA assay was fully validated.

In contrast, false positive OSNA results were also described and showed CK19 mRNA expression in lymph nodes from patients without cancer, e.g. with inflammation or benign epithelial inclusions [31, 32]. In addition, intramammary SLNs on lymphoscintigraphy are observed in $0.2 \%$ to $14 \%$ of patients and can theoretically cause a false positive result if the surrounding breast parenchyma has not been completely removed from the SLN before OSNA analysis [33-36]. The factor limiting the scope of this study is the lack of information on the location of SLN, and thus we cannot determine whether a higher rate of discordant cases occurred in the intramammary location of SLNs. In order to avoid the risk of error, some authors have proposed setting the cut-off point of the OSNA result above 250 copies/ $\mu$ l [37].

The current guidelines for cancer treatment are based on histological and not molecular criteria. However, the OSNA results proved to be more reliable than the standard histological examination of frozen sections or paraffin block and can therefore decide on further surgery and adjuvant therapy [38]. The OSNA detects nodal metastases 
of smaller size, but it is uncertain whether all patients with ITC or micrometastases require further axillary lymph node dissection, which should be the subject of further studies to establish treatment standards. When no CK19 expression in the primary tumor is observed, histological examination with $\mathrm{H}+\mathrm{E}$ staining still should be recommended.

In conclusion, the OSNA analysis is a system which allows rapid and quantitative detection of mRNA CK19, which ensures high specificity with a low rate of false positives. The OSNA is a reliable, accurate tool for intraoperative diagnosis of sentinel lymph nodes in patients with breast cancer when the whole SLN is used for analysis. Therefore, OSNA minimizes the need for secondary ALND and avoids delays in the adjuvant treatment.

\section{Acknowledgments}

Oral presentation: $2^{\text {nd }}$ EURAPS Research Council Meeting, Belek, Turkey, 22-23 May 2013.

The study was supported by statutory fund no. 2013/VII/15 from the Mother's Poland Memorial Hospital and Research Institute in Lodz, Poland.

\section{Conflict of interest}

The authors declare no conflict of interest.

\section{References}

1. Layfield DM, Agrawal A, Roche H, Cutress RI. Intraoperative assessment of sentinel lymph nodes in breast cancer. Br J Surg 2011; 98: 4-17.

2. Blumencranz P, Whitworth PW, Deck K, et al. Sentinel node staging for breast cancer: intraoperative molecular pathology overcomes conventional histologic sampling errors. Am J Surg 2007; 194: 426-32.

3. Viale G, Dell'Orto P, Biasi MO, et al. Comparative evaluation of an extensive histopathologic examination and a real-time reverse-transcription-polymerase chain reaction assay for mammaglobin and cytokeratin 19 on axillary sentinel lymph nodes of breast carcinoma patients. Ann Surg 2008; 247: 136-42.

4. Julian TB, Blumencranz P, Deck K, et al. Novel intraoperative molecular test for sentinel lymph node metastases in patients with early-stage breast cancer. J Clin Oncol 2008; 26: 3338-45.

5. Mansel RE, Goyal A, Douglas-Jones A, et al. Detection of breast cancer metastasis in sentinel lymph nodes using intra-operative real time GeneSearch BLN Assay in the operating room: results of the Cardiff study. Breast Cancer Res Treat 2009; 115: 595-600.

6. Castellano I, Macrì L, Deambrogio C, et al. Reliability of whole sentinel lymph node analysis by one-step nucleic acid amplification for intraoperative diagnosis of breast cancer metastases. Ann Surg 2012; 255: 334-42.

7. Snook KL, Layer GT, Jackson PA, et al.; OSNA Study Group. Multicentre evaluation of intraoperative molecular analysis of sentinel lymph nodes in breast carcinoma. Br J Surg 2011; 98: 527-35.

8. Tamaki Y, Akiyama F, Iwase T, et al. Molecular detection of lymph node metastases in breast cancer patients: results of a multicenter trial using the one-step nucleic acid amplification assay. Clin Cancer Res 2009; 15: 2879-84.

9. Schem C, Maass N, Bauerschlag DO, et al. One-step nucleic acid amplification - a molecular method for the detection of lymph node metastases in breast cancer patients; results of the German study group. Virchows Arch 2009; 454: 203-10.

10. Visser M, Jiwa M, Horstman A, et al. Intra-operative rapid diagnostic method based on CK19 mRNA expression for the detection of lymph node metastases in breast cancer. Int J Cancer 2008; 122: 2562-7.

11. Sobin LH, Wittekind C. TNM Classification of Malignant Tumors. $6^{\text {th }}$ ed. Wiley-Liss, New York, NY 2002.

12. Godey F, Leveque J, Tas P, et al. Sentinel lymph node analysis in breast cancer: contribution of one-step nucleic acid amplification (OSNA). Breast Cancer Res Treat 2012; 131: 509-16.

13. Khaddage A, Berremila SA, Forest F, et al Implementation of molecular intra-operative assessment of sentinel lymph node in breast cancer. Anticancer Res 2011; 31: 585-90.

14. Bernet L, Cano R, Martinez M, et al. Diagnosis of the sentinel lymph node in breast cancer: a reproducible molecular method: a multicentric Spanish study. Histopathology 2011; 58: 863-9.

15. Feldman S, Krishnamurthy S, Gillanders W, et al.; US OSNA Amplification Clinical Study Group. A novel automated assay for the rapid identification of metastatic breast carcinoma in sentinel lymph nodes. Cancer 2011; 117: 2599-607.

16. Cutress RI, McDowell A, Gabriel FG, et al. Observational and cost analysis of the implementation of breast cancer sentinel node intraoperative molecular diagnosis. J Clin Pathol 2010; 63: 522-9.

17. Krishnamurthy S, Meric-Bernstam F, Lucci A, et al. A prospective study comparing touch imprint cytology, frozen section analysis, and rapid cytokeratin immunostain for intraoperative evaluation of axillary sentinel lymph nodes in breast cancer. Cancer 2009; 115: 1555-62.

18. Holck S, Galatius H, Engel U, Wagner F, Hoffmann J. False-negative frozen section of sentinel lymph node biopsy for breast cancer. Breast 2004; 13: 42-8.

19. Degnim AC, Griffith KA, Sabel MS, et al. Clinicopathologic features of metastasis in nonsentinel lymph nodes of breast carcinoma patients. Cancer 2003; 98: 2307-15.

20. Viale G, Maiorano E, Pruneri G, et al. Predicting the risk for additional axillary metastases in patients with breast carcinoma and positive sentinel lymph node biopsy. Ann Surg 2005; 241: 319-25.

21. Weaver DL. Pathology evaluation of sentinel lymph nodes in breast cancer: protocol recommendations and rationale. Mod Pathol 2010; 23 (Suppl. 2): S26-32.

22. de Boer M, van Dijck JAAM, Bult P, Borm GF, Tjan-Heijnen VCG. Breast cancer prognosis and occult lymph node metastases, isolated tumor cells, and micrometastases. J Natl Cancer Inst 2010; 102: 410-25.

23. de Boer M, van Deurzen CH, van Dijck JA, et al. Micrometastases or isolated tumor cells and the outcome of breast cancer. N Engl J Med 2009; 361: 653-63.

24. Daniele L, Annaratone L, Allia E, et al. Technical limits of comparison of step-sectioning, immunohistochemistry and RT-PCR on breast cancer sentinel nodes: a study on methacarn fixed tissue. J Cell Mol Med 2009; 13: 4042-50.

25. Le Frère-Belda MA, Bats AS, Gillaizeau F, et al. Diagnostic performance of one-step nucleic acid amplification 
for intraoperative sentinel node metastasis detection in breast cancer patients. Int I Cancer 2012; 130: 2377-86.

26. Chu PG, Weiss LM. Keratin expression in human tissues and neoplasms. Histopathology 2002; 40: 403-39.

27. Alvarenga CA, Paravidino PI, Alvarenga $M$, et al. Expression of CK19 in invasive breast carcinomas of special histological types: implications for the use of one-step nucleic acid amplification. J Clin Pathol 2011; 64: 493-7.

28. Parikh RP, Yang Q, Higgins SA, Haffty BG. Outcomes in young women with breast cancer or triple-negative phenotype: the prognostic significance of CK19 expression. Int J Radiat Oncol Biol Phys 2008; 70: 35-42.

29. Vilardell F, Novell A, Martin J, et al. Importance of assessing CK19 immunostaining in core biopsies in patients subjected to sentinel node study by OSNA. Virchows Arch 2012; 460: 569-75.

30. Tamaki Y, Sato N, Homma K, et al.; Japanese OSNA Study Group. Routine clinical use of the one-step nucleic acid amplification assay for detection of sentinel lymph node metastases in breast cancer patients: results of a multicenter study in Japan. Cancer 2012; 118: 3477-83.

31. Yun K, Gunn J, Merrie AE, Phillips LV, McCall JL. Keratin 19 mRNA is detectable by RT-PCR in lymph nodes of patients without breast cancer. Br J Cancer 1997; 76: 1112-3.

32. Bostick PJ, Chatterjee S, Chi DD, et al. Limitations of specific reverse-transcriptase polymerase chain reaction targets in the detection of metastases in the lymph nodes and blood of breast cancer patients. J Clin Oncol 1998; 16: 2632-40.

33. Estourgie SH, Nieweg OE, Olmos RA, Rutgers EJ, Kroon BB. Lymphatic drainage patterns from the breast. Ann Surg 2004; 239: 232-7.

34. Intra M, Garcia-Etienne CA, Renne G, et al. When sentinel lymph node is intramammary. Ann Surg Oncol 2008; 15: 1304-8.

35. Jansen L, Doting MH, Rutgers EJ, de Vries J, Olmos RA, Nieweg OE. Clinical relevance of sentinel lymph nodes outside the axilla in patients with breast cancer. $\mathrm{Br}$ J Surg 2000; 87: 920-5.

36. Uren RF, Howman-Giles R, Renwick SB, Gillett D. Lymphatic mapping of the breast: locating the sentine lymph nodes. World I Surg 2001; 25: 789-93.

37. Tsujimoto M, Nakabayashi K, Yoshidome K, et al. Onestep nucleic acid amplification for intraoperative detection of lymph node metastasis in breast cancer patients. Clin Cancer Res 2007; 13: 4807-16.

38. Goldhirsch A, Ingle JN, Gelber RD, Coates AS, Thürlimann B, Senn HJ; Panel members. Thresholds for therapies: highlights of the St Gallen International Expert Consensus on the primary therapy of early breast cancer 2009. Ann Oncol 2009; 20: 1319-29. 